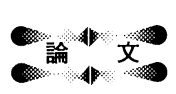

\title{
セシウムー不飽和有機分子ー三元系黒鉛層間化合物の電流磁気特性
}

\author{
松本里香*, 高橋洋一* ${ }^{*}$ 阿久沢昇**
}

(平成13年4月3日受理, 平成13年6月20日採択)

\section{Galvanomagnetic Properties of Cesium-Unsaturated Organic Molecule-Ternary Graphite Intercalation Compounds}

\begin{abstract}
Rika Matsumoto*, Yoichi Takahashi* and Noboru Akuzawa**
Electrical conductivities of Cs-unsaturated organic molecule-ternary GIC decrease gradually or rapidly in air, while their thermoelectric powers remain unchanged. For investigating their conductive carriers, electrical conductivity $(\sigma)$, Hall coefficient $\left(R_{\mathrm{H}}\right)$ and magnetoresistance $(\Delta \rho / \rho)$ of $\mathrm{CsC}_{24}\left(\mathrm{C}_{2} \mathrm{H}_{4}\right)_{\times}, \mathrm{CsC}_{24}\left(\mathrm{C}_{6} \mathrm{H}_{6}\right)_{\times}$and $\mathrm{CsC}_{24}\left(\mathrm{C}_{2} \mathrm{H}_{3} \mathrm{CN}\right)_{\times}$ were measured, and their carrier concentrations $(n)$ and mobilities $(\mu)$ were estimated. The values of $R_{\mathrm{H}}$ were negative for all the GICs investigated, thus their dominant carriers were considered to be electrons. On the other hand, the values of $\Delta \rho / \rho$ of $\mathrm{CsC}_{24}\left(\mathrm{C}_{2} \mathrm{H}_{4}\right)_{1.4}$ were too small to be detected, indicating that its electrical conduction is only through electrons, while other GICs have electrons and much less number of holes. These results indicate that all of the ternary GICs investigated maintain a certain fraction of Cs atoms between graphite layers, even after a long time of exposure to air, although some degradation of stage structure are found by XRD as the case of $\mathrm{CsC}_{24}\left(\mathrm{C}_{6} \mathrm{H}_{6}\right)_{2.1}$. This consideration corresponds well with the fact that their thermoelectric powers kept unchanged. By observing the change of the galvanomagnetic properties of the ternary GICs with time, we found that the releasing of part of Cs atoms from the interlayer nanospace occurred exclusively in the first 30 days.
\end{abstract}

KEYWORDS : $C_{S} C_{24}$, Ternary-GIC, Electrical conductivity, Hall coefficient, Magnetoresistance

\section{1. 緒 言}

アルカリ金属－黒鉛層間化合物 (Alkali Metal-Graphite Intercalation Compound; AM-GIC) はその高電気伝導性が注 目される一方, 大気下で容易に分解してしまう久点を持つ。 しかし, 高電気伝導性の他にも, AM-GICはアルカリ金属の挿 入によって生じた層間ナノスペースに水素などの気体分子を 収容する気体吸蔵能力 ${ }^{1)}$ や黑鉛や単純金属よりも一桁大きな 絶対熱電能2),3) などの特性を持つ興味深い材料である。

著者らは「高電気伝導性」と「大気下安定性」を併せ持つ AM-GIC類似化合物として, Cs-不飽和有機分子一三元系黒鉛 層間化合物に注目して研究を行っている。黒鉛層間に吸収さ れた有機分子は,アルカリ金属が層間外へ拡散・逸出するの を抑止する働きをするが, 特に, 有機分子が不飽和結合をもつ 場合は, 層間のナノスペース中でオリゴメリゼーションを起 こし, 拡散抑止効果が高まると考えられる ${ }^{4)}$ 。著者らはアルカ リ金属として, Csの他にも $\mathrm{K}$ や Rbを用いた化合物について検 討を行い, Csが最も適していることを確認した5)。特に, $\mathrm{CsC}_{24}$
にエチレンを比較的多量 $\left(\mathrm{C}_{2} \mathrm{H}_{4} / \mathrm{Cs}>1\right)$ に吸収させた場合に 高い大気下安定性が得られている6),7)。

このような有機分子による三元化がCs原子の拡散・逸出防 止に有效であるとはいえ, 大気下での電気伝導率の経時的な低 下は避けられない。比較的高い安定性を示す $\mathrm{CsC}_{24}\left(\mathrm{C}_{2} \mathrm{H}_{4}\right)_{\mathrm{x}>1}$ の場合でさえ, 電気伝導率は大気下での保持100日後には当初

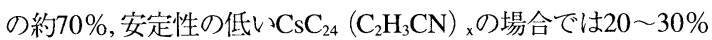
にまで減少する7)。これに対して,これら三元系GICの絶対熱 電能は大気下放置後長期にわたり, 室温でー $30 \sim 40 \mu \mathrm{V} \mathrm{K}^{-1}$ と いう大きな值を半永久的に維持する（大気下保存により熱電 能が低下した例はない)。すなわち，これらの三元系GICには， 電気伝導率の減少にかかわらず, 多数のCs原子がドナーとし て黒鉛層間に残存している可能性が高い。

本報告では, Cs-不飽和有機分子一三元系GICの伝導キャリ アに関する知見を得るために, 電気伝導率 $(\sigma)$, ホール係数 $\left(R_{\mathrm{H}}\right)$ および磁気抵抗 $(\Delta \rho / \rho)$ 測定を行った結果について述べ る。さらに, 測定值からキャリア密度および移動度を推算し, 定量的な考察を試み, Cs-不飽和有機分子一三元系GICの総括

* 中央大学理工学部応用化学科：干112-8551 東京都文京区春日1-13-27

* Department of Applied Chemistry, Chuo University : 1-13-27, Kasuga, Bunkyo-ku, Tokyo 112-8551, Japan

** 東京工業高等専門学校物質工学科：テ193-8610 東京都八王子市椚田町1220-2

** Department of Chemical Science and Engineering, Tokyo National College of Technology : 1220-2, Kunugida, Hachioji, Tokyo 1938610 , Japan 
的な評価を行った。

\section{2. 実 験}

本研究では以下に述べる2つのシリーズの実験を行った。 伐用したCs-不飽利有機分子一三元系GICはGrafoil (UCAR社 製；GTA 級）をホス卜黑鉛としてTwo-bulb法により合成し た二元系ステージ-2化合物 $\left(\mathrm{CsC}_{24}\right)$ に, エチレン, ベンゼンお よびアクリロニトリルを気体接触法で吸収させて合成したも のである。試料合成に関する詳細はすでに報告した5),8),9\%。

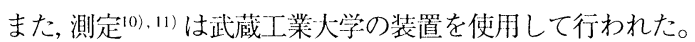

\section{1 大気下で長期間保存した後のCs-不飽和有機分子一三元 系GICの電流磁気効果測定}

測定試料には, $\mathrm{CsC}_{24}\left(\mathrm{C}_{2} \mathrm{H}_{4}\right)_{1.4}$ (以下, Cs-Et1.4と記す), $\mathrm{CsC}_{24}$ $\left(\mathrm{C}_{6} \mathrm{H}_{6}\right)_{2.1}$ (以下, Cs-Bz) およびホス卜黑鉛のGrafoilを用いた。 Cs-Et1.4およびCs-Bzは大気下でデシケータ中に 1 年以上保存 されたものであり,十分安定化している。つまり,電気伝導率 測定やX線回折測定において分解の進行は観測されない。

試料形状は約 $5 \mathrm{~mm} \times 15 \mathrm{~mm} \times 0.5 \mathrm{~mm}$ （ホストの場合，約 $5 \mathrm{~mm} \times 15 \mathrm{~mm} \times 0.3 \mathrm{~mm})$ の短冊状であり, Fig.1のように各測 定用端子を $\mathrm{Au}$ （または $\mathrm{Ag}$ )ペーストを用いて取り付け, 電気 伝導率, ホール係数および磁気抵抗測定を $77 \mathrm{~K}$ および室温で 行った。各端子は試料傾面にもペーストを塗布し, 試料表面 だけではなくバルク全体の測定となるように留意した。ホー ル係数および磁気抵抗測定は電流 $40 \mathrm{~mA}$ （または $60 \mathrm{mA）をa}$ 軸方向 (試料表面に平行) に流し, $\mathrm{c}$ 軸方向 (試料表面に垂直) に磁場 (B) 0〜1Tを印加して行った。

\section{2 大気接触直後のCs-不飽和有機分子一三元系GICの電流} 磁気効果の時間变化測定

合成終了後真空下で保存されていた $\mathrm{CsC}_{24}\left(\mathrm{C}_{2} \mathrm{H}_{4}\right)_{1.1}$ (以下, Cs-Et1.1) および $\mathrm{CsC}_{24}\left(\mathrm{C}_{3} \mathrm{H}_{3} \mathrm{CN}\right)_{1.2}$ (以下, Cs-AN) を大気下 に取り出し, 2.1 と同様の電気伝導率, ホール係数抢よび磁気 抵抗測定を77K, 1Tで行った。この測定を大気接触の翌日か ら60日間の間に3回ないし4回行い, 時間変化を観測した。た だし, Cs-Et1.1では同一ロットからの2つの測定用試片 (CsEt1.1-A,-B)を用いた。

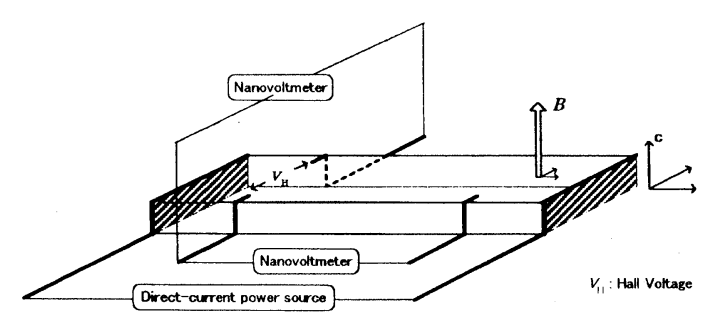

Fig.1 Experimental set-up for measuring electrical conductivity, Hall coefficient and magnetoroesistance.

\section{3. 結果と考察}

\section{1 大気下で長期間保存したCs-三元系一GICの電流磁気効果}

Cs-Et1.4, Cs-Bzおよびホスト黑鉛のGrafoilの77 Kおよび 室温に抢けるホール係数 $\left(R_{\mathrm{H}}\right)$ の結果をFig.2に, 磁気抵抗 $(\Delta \rho / \rho)$ の結果をFig.3に示す。Cs-Et1:4は電気伝導率が比較 的大きく (77KでGrafoilの6倍), GICのステージ構造 (ステー ジ-2） 5) もほぼ完全に維持している。一方, Cs-Bzは電気伝導 率が小さく(77KでGrafoilの2倍), 構造も乱れている8)。

Grafoil, Cs-Et1.4㧍よびCs-Bzのいずれも，R $R_{\mathrm{H}}$ 角の值を示 し(Fig.2), 多数キャリアが電子, すなわちn型であることが 示され, 絶対熱電能測定からの結果5) と一致した。また, Grafoil とCs-Bzの $\Delta \rho / \rho$ は磁場 $(B)$ の二乘にほほ比例したが, Cs-Et1.4では $\Delta \rho / \rho$ は観测されなかった $($ Fig.3)。 $\Delta \rho / \rho$ が観測 されたGrafoil とCs-Bzは伝導キャリアとして電子とホールが 共存する2キャリア伝導, 一方, $\Delta \rho / \rho$ 観測されなかったCsEt1.4は電子のみの1キャリア伝導である。

$\left|R_{\mathrm{H}}\right|$ と $\Delta \rho / \rho$ に対して, Grafoil $>\mathrm{Cs}-\mathrm{Bz}>\mathrm{Cs}-\mathrm{Et} 1.4$ という大小 関係が成立した。Cs-Et1.4の $\left|R_{\mathrm{H}}\right|$ はGrafoilの約10\%（77K, $1 \mathrm{~T}), \mathrm{Cs}-\mathrm{Bz} の \Delta \rho / \rho$ はGrafoilの約 $5 \%(77 \mathrm{~K}, 1 \mathrm{~T})$ と相当に小さ くなっている。このように, GICの $\left|R_{\mathrm{H}}\right| や \Delta \rho / \rho$ がスト黒鉛 の值よりも小さくなることは, さまざまなaICに関して多数 の報告 ${ }^{(2)}$ - 15) があり, キャリア数やキャリア移動度の変化が大 きく影響していると考えられている。しかし, Cs-Bzの $\left|R_{\mathrm{H}}\right|$ は

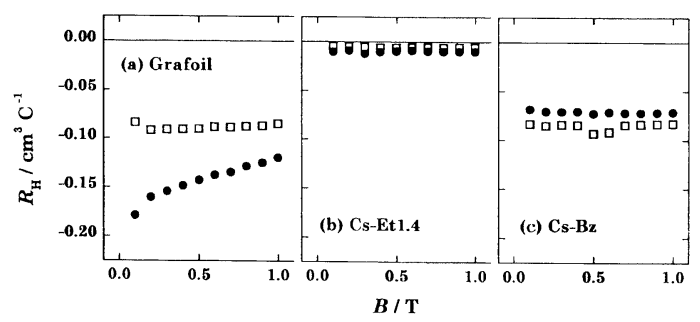

Fig.2 Hall coefficients $\left[R_{\mathrm{H}}\right]$ vs. $B$ for (a) Grafoil, (b) Cs-Et1.4 and (c) Cs-Bz: - at $77 \mathrm{~K} ; \square$, at room temperature.

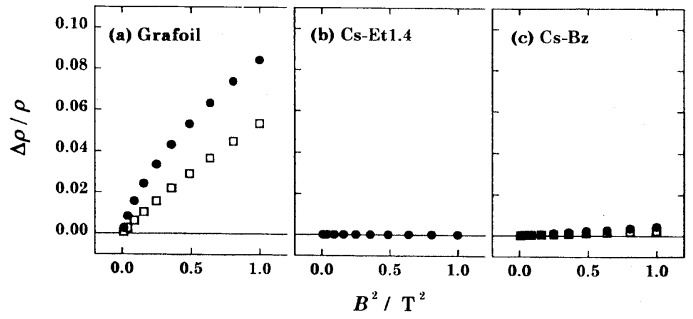

Fig.3 Magnetoresistances $[\Delta \rho / \rho]$ vs. $B^{2}$ for (a) Grafoil, (b) Cs-Et1.4 and (c) Cs-Bz: , at $77 \mathrm{~K} ; \square$, at room temperature. 
ホストであるGrafoilと比較してそれほど小さくなく, 特に筀 温ではGrafoilとほほ等しくなった。

以上の伝導キャリアに関する結果を定量的に検討するため に, 電気伝導率 $(\sigma)$, ホール係数 $\left(R_{\mathrm{H}}\right)$, 磁気抵抗 $(\Delta \rho / \rho)$ の测 定値を用いてキャリア密度 $(n)$ および移動度 $(\mu)$ を求める。

Cs-Et1.4は笔子による1キャリア伝導なので, 次の式 (1), 式 (2) から電子密度 $\left(n_{\mathrm{e}}\right)$ および移動度 $\left(\mu_{\mathrm{e}}\right)$ を求めることがで きる。ただし, eは電気素量である。

$$
\begin{aligned}
& \sigma=n_{\mathrm{c}} \mathrm{e} \mu \\
& R_{\mathrm{H}}=-\frac{1}{n_{\mathrm{e}} \mathrm{e}}
\end{aligned}
$$

一方, Grafoil とCs-Bzは電子とホールによる2キャリア伝導な ので,2キャリア伝導モデルの関係式を低磁場近似 ${ }^{16)}$ した次の 式 (3) 〜式 (5) を用いる。ただし, Bは磁場の大きさ（磁束密 度)である。

$$
\begin{aligned}
& \sigma=\mathrm{e}\left(n_{\mathrm{e}} \mu_{\mathrm{e}}+n_{\mathrm{h}} \mu_{\mathrm{h}}\right) \\
& R_{\mathrm{H}}=-\frac{1}{\mathrm{e}} \cdot \frac{n_{\mathrm{c}} \mu_{\mathrm{e}}^{2}-n_{\mathrm{h}} \mu_{\mathrm{h}}^{2}}{\left(n_{\mathrm{e}} \mu_{\mathrm{e}}+n_{\mathrm{h}} \mu_{\mathrm{h}}\right)^{2}} \\
& \Delta \rho / \rho=\frac{n_{\mathrm{e}} n_{\mathrm{h}} \mu_{\mathrm{e}} \mu_{\mathrm{h}} \cdot\left(\mu_{\mathrm{e}}+\mu_{\mathrm{h}}\right)^{2}}{\left(n_{\mathrm{e}} \mu_{\mathrm{c}}+n_{\mathrm{h}} \mu_{\mathrm{h}}\right)^{2}} \cdot B^{2}
\end{aligned}
$$

未知数は電子およびホール密度 $\left(n_{\mathrm{e}}, n_{\mathrm{h}}\right)$, それぞれの移動度 $\left(\mu_{\mathrm{c}}, \mu_{\mathrm{h}}\right)$ の4つであり,1キャリア伝導の場合のように容易に算 出することはできない。式 (3) 〜式 (5) の解法としては, パ ラメータ $\left(n_{\mathrm{e}}, n_{\mathrm{h}}, \mu_{\mathrm{e}}, \mu_{\mathrm{h}}\right)$ を順に代入して最適值を探し出す Try\&Error法 ${ }^{(5)}$ と式 (3) 〜 式 (5) を連立方程式として数值解 析的に解くNewton法17) が考えられたが, 計算スピードの速さ を重視してNewton法を採用した。しかし, Newton法の場合, 上の3式から未知パラメータを1つ減らす必要があるので, Marchand ${ }^{18)}$ に倣い次の仮定を用いた。

黒鉛の場合： $\mu_{\mathrm{e}}=\mu_{\mathrm{h}}$

GICの場合： $\left(n_{\mathrm{e}} \cdot n_{\mathrm{h}}\right)_{\text {Graphite, } T[\mathrm{~K}]}=\left(n_{\mathrm{e}} \cdot n_{\mathrm{h}}\right)_{\mathrm{GIC}, T[\mathrm{~K}]}=$ const

計算結果をTable 1にまとめた。ここで, $R_{\mathrm{H}}$ と $\Delta \rho / \rho$ の值は1T における值を用いている。Cs-Et1.4では $n_{\mathrm{e}}$ がGrafoilの680倍 に増加しているにもかかわらず, $\mu_{\mathrm{e}}$ が1/50に減少するため, 結 局のはGrafoilの6倍に留まっていることがわかる。また, 特に 注目されるのがCs-Bzである。Cs-Bzの $\sigma や R_{\mathrm{H}}$ はGrafoilの值 に近く,かつ, $\Delta \rho / \rho$ が観測されたため, 相当にGICの分解が進 行していると推察された。しかし, 式 (3) の電子による伝導 成分 $\left(n_{\mathrm{e}} \cdot \mu_{\mathrm{e}}\right)$ とホール成分 $\left(n_{\mathrm{h}} \cdot \mu_{\mathrm{h}}\right)$ を比較すると $\left(n_{\mathrm{e}} \cdot \mu_{\mathrm{e}}\right)$ $\gg\left(n_{\mathrm{h}} \cdot \mu_{\mathrm{h}}\right)$ である。つまり, 電気伝導へのホールの寄与は極

\begin{tabular}{|c|c|c|c|c|c|c|}
\hline & $\sigma$ & $\begin{array}{c}R_{\mathrm{H}} \\
\text { [at IT] }\end{array}$ & $\begin{array}{c}\Delta \rho / \rho \\
\text { [at 1T] }\end{array}$ & $n_{\mathrm{e}}$ & $n_{\mathrm{h}}$ & $\mu_{\mathrm{c}} \quad \mu_{\mathrm{h}}$ \\
\hline & $10^{3} / \mathrm{Scm}^{-1}$ & $/ \mathrm{cm}^{3} \mathrm{C}^{1}$ & $10^{-2 /-}$ & \multicolumn{2}{|c|}{$10^{17} / \mathrm{cm}^{-3}$} & $/ \mathrm{cm}^{2} \mathrm{~V} \mathrm{~s}^{1}$ \\
\hline Grafoil & 0.746 & -0.12 & 8.4 & 8.3 & 7.8 & 2900 \\
\hline Cs-Et1.4 & 4.61 & -0.011 & - & 5700 & - & $51-$ \\
\hline $\mathrm{Cs}-\mathrm{Bz}$ & 1.42 & -0.072 & 0.43 & 530 & 0.12 & 1706700 \\
\hline
\end{tabular}

Table 1 Values of electrical conductivity $[\sigma]$, Hall coefficients $\left[R_{\mathrm{H}}\right]$, magnetoresistance $[\Delta \rho / \rho]$, carrier mobilities $\left[\mu_{\mathrm{c}}, \mu_{\mathrm{h}}\right]$ and carrier concentrations $\left[n_{\mathrm{c}}, n_{\mathrm{h}}\right]$ for Grafoil, Cs-Et 1.4 and Cs-Bz at $77 \mathrm{~K}$.

めて小さく, Cs-Bzの場合も, ほぼ電子のみの1キャリア伝導に 近いと考えることができる。したがって, Cs-不飽和有機分 子一三元系GICはののみから想定されるよりも大きな $n_{\mathrm{c}} を も$ ち, 黒鉛層間には多数のCs原子がドナーとして存在している ことが示唆された。このことは, Cs-不飽和有機分子一三元系 GICが常に大きな負の絶対熱電能を示すこととよく対応する。

\section{2 大気接触直後のCs-三元系－GICの電流磁気効果}

前節において, 1 年以上の大気下保存にもかかわらずCs-不 飽和有機分子一三元系GICにはかなりの割合のCs原子が層間 に存在していることが示呶された。ここではGICを大気に接 触させた直後からの電流磁気効果, キャリア密度および移動 度の経時変化について検討する。試料としては,これまでの

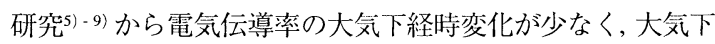
安定性の高いCs-Et1.1と, 逆に大気下安定性の低いCs-ANの2 つのGICを取り上げた。

Cs-Et1.1およびCs-ANの大気との接触直後から60日間の, $77 \mathrm{~K}$ における $\sigma, R_{\mathrm{H}}, \Delta \rho / \rho$ の経時変化をFig.4に示す。なお, Cs$\mathrm{AN} の \sigma$ 值の一部 [図中 ( ) で表示] は $R_{\mathrm{H}} や \Delta \rho / \rho$ と同時に测定

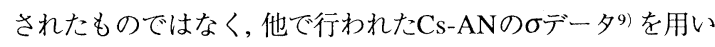
て妥当と思われる外挿を施して求めた推定值である。また, Cs-Et1.1-Aと-Bの $\Delta \rho / \rho$ に見られる不連続は, 測定誤差の範囲 内である。この結果より, Cs-Et $1.1, \mathrm{Cs}-\mathrm{AN} と も に \sigma, R_{\mathrm{H}}, \Delta \rho / \rho$ の各值は時間とともにGrafoilの值に近づく方向, すなわち分 解の方向に変化したが, Cs-ANの変化は大気下安定性の差異 を反映して,Cs-Et1.1よりも相当に大きくなった。

また, 大気接触初期のCs-ANののはCs-Et1.1のほほ2倍と大 きいが, 時間とともに急激に減少し, Cs-Et1.1の約 $1 / 2$ の值に収 束した。このように, $\mathrm{CsC}_{24}\left(\mathrm{C}_{2} \mathrm{H}_{3} \mathrm{CN}\right)_{\mathrm{x}}$ の初期 $\sigma$ が $\mathrm{CsC}_{24}$ $\left(\mathrm{C}_{2} \mathrm{H}_{4}\right)_{\mathrm{x}}$ よりも大きいことは,これまでにも観測されている19)。 通常, $\mathrm{CsC}_{24}$ に分子が吸収された場合, 黒鉛網面からインター カレートへの電子のバックドネーションが生じるため $n_{\mathrm{e}} や \sigma$ は減少する12)。しかし, 高重合性のアクリロニトリルの場合, 黒鉛層間侵入前に試料表面や端部で一部の分子が重合を起こ すため7), アクリロニトリルによる層間ナノスペースの充填 が不十分である個所が存在すると考えられる。つまり, Cs$\mathrm{AN}$ 結晶子内部には部分的に二元系 $\left(\mathrm{CsC}_{24}\right)$ 的な個所が存 在するが故に, Cs-ANの $\sigma$ は大気接触初期のみ大きく, 時間と ともに速やかに減少すると推察される。

以上の推論は吉岡ら ${ }^{9}$ による $\mathrm{CsC}_{24}\left(\mathrm{C}_{2} \mathrm{H}_{3} \mathrm{CN}\right)_{1.4}$ に対するX 
線回折パターンの経時測定の結果とよく対応する。すなわち, 大気接触直後, $\mathrm{CsC}_{24}\left(\mathrm{C}_{2} \mathrm{H}_{3} \mathrm{CN}\right)_{1.4}$ にはアクリロニトリル分子 が部分的にしか挿入されていない (二元系的構造) と思われ るピークが観測されるが, 翌日には消滅する。この現象は本 研究でのCs-ANにおいても観測されており, $\mathrm{CsC}_{24}\left(\mathrm{C}_{2} \mathrm{H}_{3} \mathrm{CN}\right)$ x の結晶子からのCs原子の拡散・逸出に対応寸ると考えられ る。しかし, 大気接触30日経過後のCs-ANのX線回折パター ンからは, Cs原子とアクリロニトリル分子がともに層間に存 在する三元系ステージ-2構造を維持していることが示唆され る。したがって, Cs-ANから一部のCs原子は拡散・逸出し, 結 晶子端部を中心にのが低下するものの, 結晶子内部のかなりの 部分にはCs原子とアクリロニトリル分子とが共存している層 面が存在すると予想される。

Cs-Et1.1, Cs-ANともに有意の $\Delta \rho / \rho$ 観測されているため, 2 キャリアモデルとして電子とホールの密度 $\left(n_{\mathrm{c}}, n_{\mathrm{h}}\right)$ および 移動度 $\left(\mu_{\mathrm{c}}, \mu_{\mathrm{h}}\right)$ の推算を行い, 結果をFig.5およびFig.6に示し た。この計算において推定值の $\sigma$ 用いたときの結果は図中 （）で示してあるが図に見られるように相対的な変化や傾 向を議論する上では大きな問題はない。Fig.5によれば, 大気

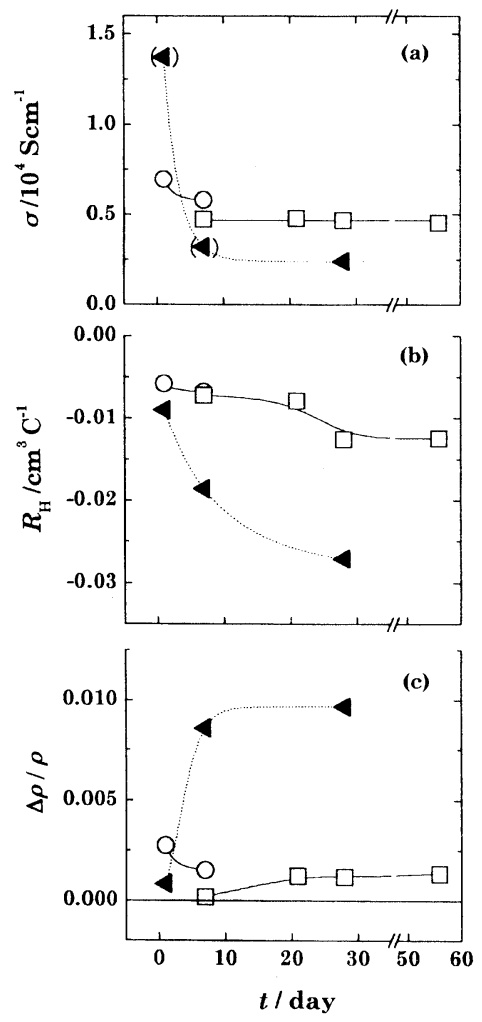

Fig.4 Change of (a) electrical conductivities $[\sigma]$, (b) Hall coefficients $\left[R_{\mathrm{H}}\right]$ and $(\mathrm{c})$ magnetoresistances $[\Delta \rho / \rho]$ with time $[t]$ in air at $77 \mathrm{~K}: \bigcirc$, Cs-Et1.1-A; $\square$, CsEt1.1-B; $\boldsymbol{\Delta}$, Cs-AN; $(\boldsymbol{\Delta})$, see text.
接触初期のCs-Et 1.1 とCs-ANのn 0 差は小さいが, Cs-ANの $n_{\mathrm{c}}$ のみ時間とともに大きく減少している。つまり，上述した大 気接触当初のCs-Et 1.1 とCs-ANの $\sigma$ 值の違いは $n_{\mathrm{c}}$ の大きさよ りも, $\mu_{\mathrm{c}}$ に主に起因するものであることがわかる。また, 電子， ホールともに $\mu$ の変化は $n$ に比べて小さく, 大気下での $\sigma$ の減 少は $n_{\mathrm{c}}$ の減少を直接反映していることが明らかとなった。

Fig.7は電子による伝導成分 $\left(n_{\mathrm{c}} \cdot \mu_{\mathrm{e}}\right)$ とホールによる伝導 成分 $\left(n_{\mathrm{h}} \cdot \mu_{\mathrm{h}}\right)$ の時間変化である。Cs-Et1.1およびCs-ANとも

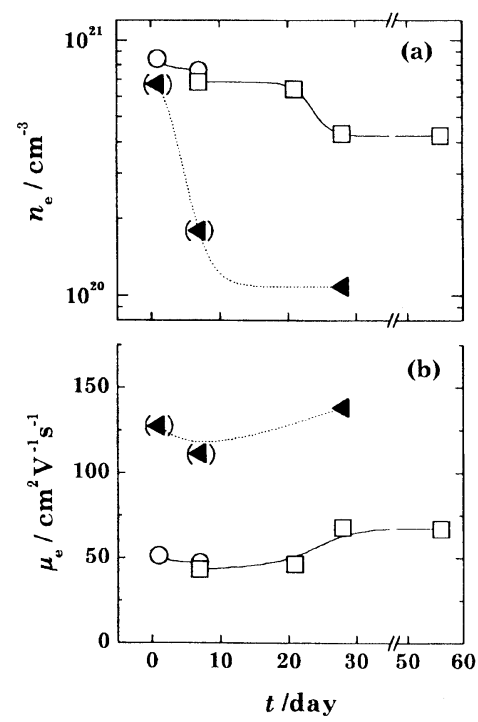

Fig.5 Change of (a) electron concentrations $\left[n_{\mathrm{c}}\right]$ and (b) electron mobilities $\left[\mu_{\mathrm{c}}\right]$ with time $[t]$ in air at $77 \mathrm{~K}: \bigcirc$, CsEt1.1-A; $\square$, Cs-Et1.1-B; $\mathbf{\Delta}$, Cs-AN; $(\boldsymbol{\Delta})$, see text.

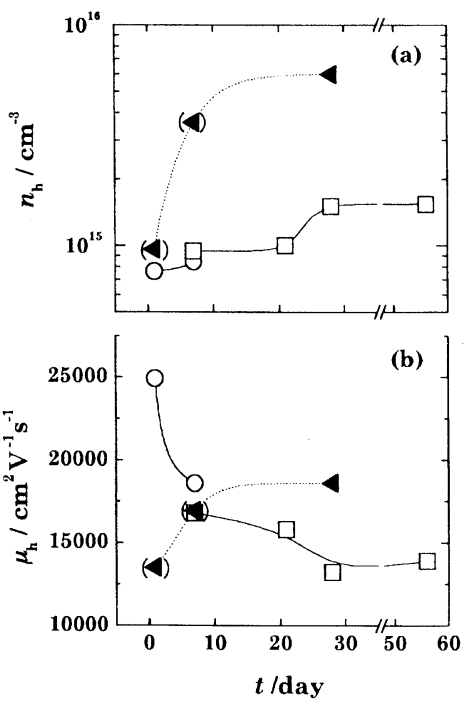

Fig.6 Change of (a) hole concentrations $\left[n_{\mathrm{h}}\right]$ and (b) hole mobilities $\left[\mu_{\mathrm{h}}\right]$ with time $[t]$ in air at $77 \mathrm{~K}: \bigcirc$, Cs-Et1.1A; $\square$, Cs-Et1.1-B; $\boldsymbol{\Delta}$, Cs-AN; $(\boldsymbol{\Delta})$, see text. 

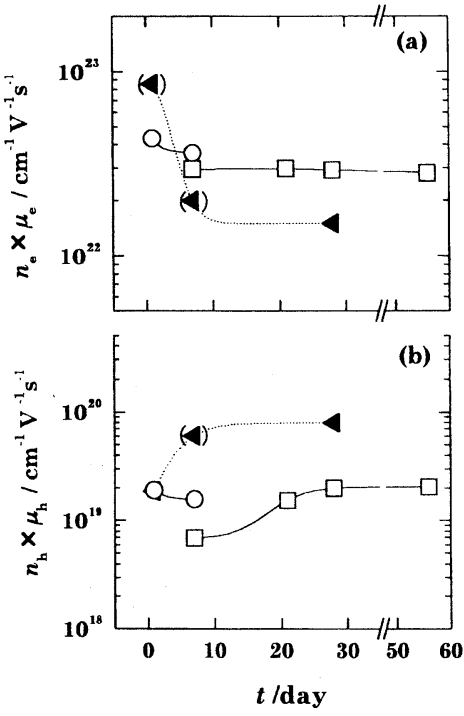

Fig.7 Change of $\{$ concentration $[n] \times$ mobility $[\mu]\}$ with time $[t]$ in air (a) electron and (b) hole at $77 \mathrm{~K}: \bigcirc$, CsEt1.1-A; $\square$, Cs-Et1.1-B; $\boldsymbol{\Delta}$, Cs-AN; ( $\mathbf{\Delta})$, see text.

に, 時間経過により電子伝導成分が減少し,ホール伝導成分が 増加する。測定期間が必ずしも十分ではないが, 大気接触30 日程度で, それらは収束に向かうようである。また, Cs-Bzと 同様に, Cs-Et1.1およびCs-ANのホールの電気伝導への寄与 は無視できるほど小さく, $\sigma \propto\left(n_{\mathrm{e}} \cdot \mu_{\mathrm{e}}\right)$ と考えられる。

大気下で比較的安定なCs-Et1.1に関してもCs-ANと同様の $n_{\mathrm{e}}$ の隇少か認められた。これは黒鉛層間のCs原子数の減少を 反映するものであろう。すなわち, 大気接触初期は一時的に Cs原子の一部が層間外へ逸出するが, 30 日程度でCs原子の拡 散・逸出は落ち着き, 残りの大部分のCs原子は黒鉛層間内に 残存すると推論される。

\section{4. 結 言}

代表的なCs-不飽和有機分子一三元系黑鉛層間化合物の電 流磁気効果測定およびキャリア密度・移動度の推算により以 下のことが明らかとなった。

Cs-不飽和有機分子一三元系黑鉛層間化合物の電気伝導率 はホスト黑鉛の2 6倍程度であるが, ホール係数が負 $\left(R_{\mathrm{H}}<\right.$

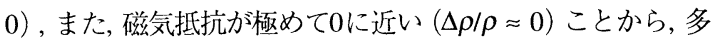
数の電子による金属的な電気伝導機構をもつ。電子の他に正 孔が存在する場合も, 電気伝導率に影響しないほどの少数で ある。また, 大気接触後の少なくとも 30 日程度の期間はCs原 子が層間外一逸出するため, 伝導電子数が減少し, 結局, 電気 伝導率が減少する。しかし, 電気伝導率の大小にかかわらず 黒鉛層間には多数のCs原子がインターカレートとして存在 しここれにより大きな絶対熱電能を示す。
今回の結果は, 不飽和絬合をもつ有機分子, とりわけエチレ ンによる $\mathrm{CsC}_{24}$ の三元化効果の有効性を改めて示すものであ り, 同時に, Cs-エチレンー三元系GICの実用化材料としての 可能性を示唆するものであると考えている。

\section{謝 辞}

電流磁気効果測定に装置を使用させていただくなど便宜を はかって頂いた武蔵工業大学鏑木 裕教授に深く感謝致しま す。また, 本研究の遂行に協力頂いた中央大学卒業研究学生 山本泰照君ならびに渡邊敬祐君に感謝します。

本研究は, 日本学術振興会未来開拓学術研究推進事業の研 究プロジェクト「炭素材料中への機能性ナノおよびミクロス ペースの創製」(JSPS-RFTF96R11701) の一環として行われ たものである。

\section{文 献}

1) Y. Takahashi and N. Akuzawa, J. Mater. Sci. Soc. Jpn. 32 (1995), 226-231 [in Japanese].

2) L. C. F. Blackman, J. F. Mathews and A. R. Ubbelohde, Proc. R. Soc. 258A (1960), 339-349.

3) J. Heremans, J-P. Issi, I. Zabala-Martinez, M. Shayegan and M. S. Dresselhaus, Phys. Lett. 84A (1981), 387-389.

4) H. Pilliere, Y. Takahashi, T. Yoneoka, T. Otosaka and N. Akuzawa, Syn. Met. 59 (1993), 191-199.

5) R. Matsumoto, Y. Takahashi, T. Yoshioka, M. Osaki, I. Kumamoto and N. Akuzawa, TANSO 1998 [No.184] 194198 [in Japanese].

6) 中野雅之, 佐藤由香, 村上幹智雄, 阿久沢昇, 松本里香, 高 橋洋一, 第26回炭素材料学会年会, 長野, 1999.12.1-3, p.23.

7) R. Matsumoto, Y. Takahashi and N. Akuzawa, Mol. Cryst. and Liq. Cryst. 340 (2000), 43-48.

8) Y. Takahashi, R. Matsumoto, T. Yoshioka, K. Tobita, M. Osaki, I. Kumamoto and N. Akuzawa, International Symposium on Carbon, Japan, I1 1-08 (1998).

9) T. Yoshioka, R. Matsumoto, Y. Takahashi and N. Akuzawa, TANSO 2001 [No.196] 19-21 [in Japanese].

10) Y. Kaburagi and Y. Hishiyama, TANSO 1990 [No.145] 327-338 [in Japanese].

11) Y. Kaburagi, TANSO 1998 [No.185] 332-335 [in Japanese].

12) N. Akuzawa, S. Kondow, Y. Kaburagi, Y. Hishiyama and Y. Takahashi, Carbon 31 (1993), 963-968.

13) M. S. Dresselhaus and G. Dresselhaus, Adv. in Phys. 30 (1981), 139-326.

14) O. El-Shazly, S. G. Tawfik, A. K. Ibrahim, I. H. Ibrahim and E. F. El-Wahidy, J. Phys. D : Appl. Phys. 26 (1993), 1268-1273.

15) Y. Soneda, Dr. Thesis, Faculty of Engineering, Hokkaido University, Sapporo, 1993.

16）菱山幸有,改訂炭素材料入門（炭素材料学会編）(1984）, pp.41-53,リアライズ社.

17）例えば, 新濃清志, 船田哲男, 数值解析の基礎, (1991), pp.53-56, 培風館.

18) A. Marchand and R. Mathur, Carbon 27 (1989), 349-357.

19）高橋洋一, 高橋英生, 石川裕子, 阿久沢昇, 第23回炭素材 料学会年会, 茨城, 1999.12.4-6, 2A07. 